\title{
Periconceptional stress in C57BL/6J female mice leads to altered behavioral responses in their offsprings
}

\author{
Alexander Oderhowho ${ }^{1,2}$ and Maria Victoria Tejada-Simon ${ }^{1,3,4,5^{*}}$
}

*Correspondence: mvtejada-simon@uh.edu

CrossMark
$\leftarrow$ Click for updates

'Department of Pharmacological and Pharmaceutical Sciences, University of Houston, Houston, TX, USA.

${ }^{2}$ Department of Biochemistry, University of Houston, Houston, TX, USA.

${ }^{3}$ Department of Psychology, University of Houston, Houston, TX, USA.

${ }^{4}$ Department of Biology, University of Houston, Houston, TX, USA.

${ }^{5}$ Biology of Behavior Institute (BoBI), University of Houston, Houston, TX, USA.

\begin{abstract}
Maternal psychological disturbance has deleterious responses on the newborn. However, the consequences of periconceptional stress in females on the behavioral effects of the offsprings have not been well established. This study was carried out to determine the predisposition to psychotic-like effects among mice derived from mothers suffering stress before conception. Ten female mice were randomly selected to two different groups, a stressed induced group and a control undisturbed group. These female mice were housed together with males to encourage pregnancy. Female mice from the stressed group were exposed daily to randomized stress test protocols. All stress tests ceased before pups were born. After birth, pups were allowed to remain with the mother until weaned at 21 days. Testing for behavioral abnormalities related to cognition and anxiety was performed in mothers as well as offsprings to calculate predisposition to psychosis and anxiety among identically treated mice. Our results indicate that periconceptional induction of stress in young females results in anxiety. Moreover, this maternal stress translated in increased anxiety-like behaviors in their youths. These results suggest that offspring of mothers stressed before conception may show enhanced responsiveness to stress later in life, and indicate that prenatal stress may have long-term effect on behavioral reactivity. Thus, it is possible that the emotional status of an adult may be ruled not only by individual post-natal occurrences, but by other earlier environmental factors related to pre-pregnancy experiences.
\end{abstract}

Keywords: Schizophrenia, stress, cognition, learning, psychosis

\section{Introduction}

It is well known that disorders of the mind normally encompass deficits in behavior. Among the more threatening disorders of this kind, we have schizophrenia, anxiety, depression and bipolar disorders. Extensive research has suggested that schizophrenia is a multi-factorial disease that can be attributable to both genetic and environmental elements $[\mathbf{1 , 2}]$. Since schizophrenia affects the global population, worldwide studies have attempted to determine which individuals would be at an elevated risk of developing this neurophysiological disorder. Studies have indicated a correlation between an individual developing neurological deficits and having a family history of psychosis $[3,4]$, with a twofold increase in risk compared to individuals without psychosis family background [5]. Moreover, approximately $20 \%$ of children with schizophrenic parents present some type of neurological impairments as compared to less than $6 \%$ of those with non-psychotic parents [5]. Psychosis might be also gender specific, with more incidences occurring in females $[\mathbf{5 , 6}$. Thus, vulnerability in developing the disease increases with a family history of schizophrenia, and/or if the offspring were female.

Also interesting is the fact that nurture plays an important role in the genesis of psychopathology. It has been shown that prenatal, perinatal and postnatal stresses affect the neurophysiology of the brain in the offspring resulting in schizophrenic-type behaviors, effects on cognition and learning and alterations in language functioning and IQ [7]. Many scientific papers have 
detailed the debilitating effects of stress on a pregnancy [8]. It has been suggested that prenatal exposure to adverse life events such as infections $[\mathbf{9 , 1 0}]$, death of a close relative [11], smoking $[12,13]$ or natural disasters [14] might lead to mental complications of the offspring, including depression, psychosis and learning disorders. Therefore, besides genetic components that might lead to neurophathological illnesses, susceptibility to these disorders appears to be enhanced by maternal exposure to some stressful factor(s) during pregnancy. In this study we focus on describing whether periconceptional maternal chronic stress produces behavioral and cognitive impairment in the offspring when reaching puberty. Specifically we were interested in determining predisposition to psychotic- and anxiety-like effects among mice derived from mothers stressed before conception. Together, our data indicate that this maternal stress induces mostly anxiety-related effects not only in the individuals undergoing the stress, but also in their future young. This might suggest that emotional status of an adult may be determined not only by familial genetic factors, but also by epigenetic changes induced upon negative environmental experiences previous to conception.

\section{Materials and methods Animals}

All experiments were conducted under an approved protocol from the University of Houston Institutional Animal Care and Use committee and according to NIH guidelines for the care and use of laboratory animals. Adult male and female C57BL/6 mice (5-7 weeks old) were used for these experiments. Females were paired with males for mating purposes. Paired animals and litters were housed in a 10:14 light/dark cycle under controlled temperature $\left(21^{\circ} \mathrm{C}\right)$ and humidity (50-55\%), with access to food and water $\mathrm{ad}$ libitum. All behavioral test described were run during the afternoon and approximately at the same time each day for all groups.

\section{Stress induction protocols}

The experimental design and protocols followed are depicted in Figure 1. Females were exposed to one of several forms of stressinducing environments, on a rotational basis and at relatively the same time each day for an average of 12-15 days. These protocols have been widely used to induce stress and validated by other laboratories. Thus, testing female mothers on anxiety, stress and cognitive behaviors after stress induction was completed just to confirm that the stress paradigms were indeed effective.

\section{Immobilization}

Mice were placed in a clear flat bottom rodent restrainer (1.5" diameter x 3.75 " long) with sufficient holes for respiration, for 30 minutes. Mice were unable to perform any form of motility (going forwards and backwards, or turning around).

\section{Shock}

Mice were place in a fear conditioning apparatus. A mild $0.45 \mathrm{~mA}$ shock lasting 3 seconds was randomly administered five times over a 7 minutes period.

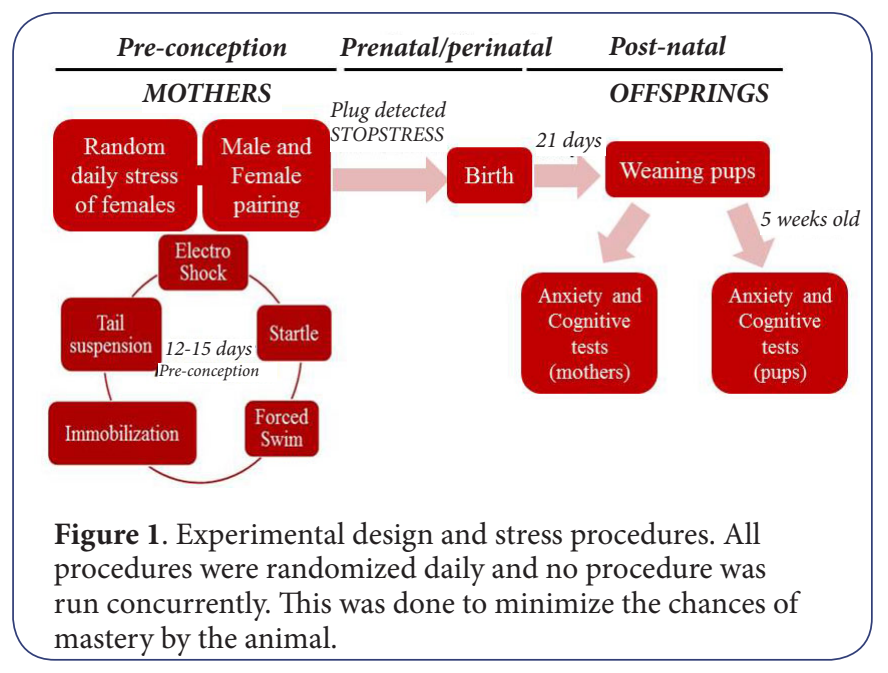

\section{Tail suspension}

Using tape, mice were suspended by the tail in the middle of a plastic chamber with the tip of the nose about 2" above the floor, for 5 minutes. When the test ended, tape was carefully removed and mice were returned to their home cages.

\section{Startle}

Mice were placed in a clear acrylic tube $(37 \mathrm{mmx} 124 \mathrm{~mm})$ with ventilation holes, and subjected to a sound with $120 \mathrm{~dB}$ intensity for $5 \mathrm{~min}$.

\section{Forced swim}

Mice were placed in a plastic cylinder or beaker without any edges. The tank was filled with $6 \mathrm{~cm}$ of water at room temperature. For about 10 minutes, mice were dropped in the tank forced to continuously swim in order to keep afloat. After the test, mice were removed from the water, carefully dried using a towel and place in their home cage to fully dry under a warm light.

Body weight and general appearance of mice were observed. After the litter was born, males were removed, newborns were allowed to remain with the mother, then weaned after 21 days. Finally, the offsprings were permitted to develop to 5-7 weeks. Both mothers and offspring were exposed to a battery of behavioral tests as described below. All equipment was cleaned with $70 \%$ ethanol solution between mice. All stress procedures were randomized daily and no procedure was run concurrently. This was done to minimize the chances of mastery by the animal.

\section{Behavioral tests}

Behavioral tests were conducted on adult mothers (to confirm induction of stress) and offsprings. Tests were conducted using low intensity light when required (e.g., open field, elevated plus maze) and from least to most strenuous to avoid potential impairments in performance throughout according to a battery of behavioral tests designed following the reference of previous expert laboratories $[\mathbf{1 5}, \mathbf{1 6}]$. The identity of the experimental group was kept blind until all analyses were performed. Behavioral 
experiments were conducted in the same sets of animals to (1) lower cost and breeding time, and (2) be consistent with good animal care and use guidelines for minimizing the numbers of animals used in biomedical research.

\section{Open field}

The mouse was place in the center of a clear plexiglass chamber $(43 \times 43 \times 18 \mathrm{~cm})$ with a lid containing $281-\mathrm{cm}$ holes covering the chamber. The animals remained in the chamber for a total of $30 \mathrm{~min}$ to explore the novel environment. Exploration by the animal was monitored by an OptoMax computer program (OptoVarimex-Micro, Columbus Instruments, Columbus, $\mathrm{OH}$ ).

\section{Accelerating rotarod}

The rotating rod $(3 \mathrm{~cm}$ in diameter, MED Associates, St. Albans, VT) was equipped with automatic fall detector, with the speed of rotation increasing at a constant rate from 4-40 rpm during a 5 min period. Each animal was tested over a period of 2 days with 4 trials/day (30 min inter-trial interval [ITI]). A single trial lasted from the time the animal was placed on the rod until it dropped off onto the plastic rest platform or until 5 min had elapsed.

\section{Pre-pulse inhibition of startle response}

The test session lasted for about 16 minutes during which the mice were given seven trial types repeated five times to make a total of six trials. Mice were placed in a plexiglas cylinder enclosed in a sound-attenuated startle chamber (SR-LAB ${ }^{\text {TM }}$ Startle Response System by San Diego Instruments, San Diego, California) and allowed to acclimate for about 5 minutes before the test session, which lasted about 10 minutes. Trial types included a no stimulus trial presented to measure baseline movement in the cylinder; a startle alone trial of $40 \mathrm{~ms}$ at $120 \mathrm{~dB}$ to measure maximum startle response and 5 trial types composed of five different $20 \mathrm{~ms}$ prepulse sounds of $74,78,82,86$, or $90 \mathrm{~dB}$ presented $100 \mathrm{~ms}$ before the startle stimulus of $120 \mathrm{~dB}$. Repetition of trial types was done in a pseudorandom manner with an inter-trial interval of about 10-20 seconds. The whole body flinch amplitude of the mouse, which occurred upon hearing the sound was measured by an electrostatic sensor located directly below the plexiglass cylinder. Recording of the startle response was done every $1 \mathrm{~ms}$ for a period of $65 \mathrm{~ms}$ following the onset of the startle stimulus. The maximum startle amplitude which was used as the dependent variable was averaged for the 6 trials for each mouse and used to calculate the percent PPI as 100 -[(startle response on acoustic prepulse plus startle stimulus trials/startle response alone trials)-100] [17].

\section{Hot plate}

This test used a hotplate analgesic meter (Columbus Instruments, Columbus, Ohio) and it is vital to learning in fear conditioning paradigm. Mice were placed, one at a time, onto a hotplate (25.4 $\mathrm{cm} \times 25.4 \mathrm{~cm}$ ) preheated to $55^{\circ} \mathrm{C}$. Latency to respond by jumping, hindpaw licking or hindpaw flicking was measured, and at that time the animal was immediately removed from the hotplate. If no response was obtained after 30 seconds, the animal was removed from the hot plate and the test ended.

\section{Light-dark exploration}

The animals were removed from the home cage and placed into a chamber $(40 \times 21 \times 17 \mathrm{~cm})$ partitioned into two sections, one illuminated by standard room lighting conditions and the other section dark. The two compartments were connected by a $7.5 \times 7.5 \mathrm{~cm}$ doorway. The mouse was placed into the illuminated portion of the chamber and allowed to explore freely. The time the mouse spent in each section was recorded.

\section{Elevated plus-maze}

This apparatus consists of four runways $(5 \mathrm{~cm} \times 30 \mathrm{~cm})$ arranged perpendicularly and elevated about 1 meter above the floor. Two arms are enclosed by $15.5 \mathrm{~cm}$ grey plexiglass walls and the other two arms are open. Mice were placed in the center of the maze and allowed to explore the open or closed arms for $10 \mathrm{~min}$. More fearful mice spent a greater percentage of time in the center of the arms with sidewalls, than on the open arms. A camera connected to a computer program (Ethovision XT tracking system, Noldus Information Technology, Leesburg, VA) recorded from above the activity and the time spent in the enclosed or the open arms. At the end of the experimental trial, the animals were lifted from the maze and returned into their home cage.

\section{Contextual and cued fear conditioning}

The experiments were carried out employing a computercontrolled fear conditioning system and software from MED Associates (St. Albans, VT), which has been previously validated [18]. Animals were placed into a mouse conditioning chamber $(13 \times 10.5 \times 13 \mathrm{~cm})$ equipped with a house light $(28 \mathrm{~V})$, a loudspeaker, and a floor with 19 equally space metal rods $(2.8 \mathrm{~mm}$ diameter). The fear conditioning chambers are housed in soundattenuating cubicles $(56 \times 50 \times 41 \mathrm{~cm})$ equipped with a background noise-generating fan to overshadow extraneous sounds. Animals were given $2 \mathrm{~min}$ to explore the environment. A $30 \mathrm{sec}$ tone $(80 \mathrm{~dB}$, $2 \mathrm{kHz})$ preceded a 2 -sec scrambled foot shock $(0.75 \mathrm{~mA})$, which was presented $120 \mathrm{sec}, 240 \mathrm{sec}$ and $360 \mathrm{sec}$ after session onset. The session ended $60 \mathrm{sec}$ after the third shock. The occurrence of freezing (defined and measured as immobility, except for respiratory movements) during this training was measured and considered the control measure of unconditioned fear. Recording of freezing behavior during experiments was automated, with the movement of mice detected by infrared cameras enclosed within each chamber. The grid-floor stimulator was calibrated with a software-integrated ammeter (MED Associates) to deliver $0.75 \mathrm{~mA}$ of $2 \mathrm{sec}$ duration. This task allowed us to assess not only contextual conditioning, a hippocampal-dependent task, but also conditioning to a discrete cue, a largely hippocampalindependent task [19-22]. After initial training, mice were then returned to their home cage. To test fear conditioning to 
the contextual cues, the animals were returned to the training context at various times after training (1-short term memory [STM] and 24-long term memory [LTM] hours) for a 7-min test session. No shocks were presented during the contextual test session. Time spent freezing in the identical test chamber was considered a measure of contextually conditioned fear, and evaluated as learning/memory behavior. To test conditioning to the tone, the test chamber was modified with respect to tactile, spatial, visual, and olfactory properties to create a novel test environment. No foot shock was administered but the same tone delivered while training was presented during the last three minutes of the test session. Freezing behavior was scored at the same time intervals to measure STM and LTM.

\section{Spatial learning in the morris water maze}

This is a spatial navigation task that teaches to locate a hidden escape platform in a circular pool $(1.38 \mathrm{~m}$ diameter Nalgene pool) of opaque water (made opaque with tempera paint powder) using distal visual cues outside the pool. Each mouse was given 4 trials a day (with inter-trial interval [ITI] of $30 \mathrm{~min}$ ) for 4 days. Subjects were released into the pool from 1 of 4 starting positions, and the location of the platform remained constant throughout training. The time to find the escape platform was measured. The amount of time any individual mouse spent in the water was limited to $60 \mathrm{sec}$. Twenty four hours following training trial number 16 (day 5), a probe test was given. In the probe test, the platform was removed and animals were allowed to search the pool for $60 \mathrm{sec}$. Quadrant search time (\%) was assessed to characterize the mouse's search behavior and recall. For all parts of this test, animal behavior was assessed using the Ethovision XT software and tracking system (Noldus, Leesburg, VA). Inability to swim or no movement resulted in early removal from the pool and not inclusion in the test group.

\section{Statistical analysis}

All data are presented as mean \pm standard error of the mean (SEM), and significance was set at $p \leq 0.05$. For PPI and Morris Water Maze, statistical assessment was done using ANOVA. For all other behavioral assessments, a $t$-test was used to compare undisturbed and stressed animals.

\section{Results}

Periconceptional induction of stress in pregnancy success rate and mouse body weight

Compared to the control undisturbed group, induction of stress in young female mice proved to have a negative effect in the success of those animals to become pregnant as well as in the mortality rate of the newborns (Table 1). Females in the control group had a better success rate on becoming pregnant compared to the stressed group. Interestingly, litter size was about $80 \%$ higher in the stress-induced group, but mortality rate of those newborns was also higher for this group compared to their undisturbed group. Body weight and weight gain for the adult females at the start and finish of experiments was not significantly different between undisturbed and stressed mothers, with undisturbed females gaining slightly more weight during their pregnancy compared to the stressed group $(t=2.05$, $p=0.0566$ ). Litters had similar weights at the time of performing the behavioral tests $(25.06 \pm 1.69$ for young animals derived from undisturbed mothers vs. $26.73 \pm 0.5$ for young animals derived from stress mothers). A similar number of males and females were tested for each group (undisturbed 5 females and 4 males $[n=9]$; stressed 6 females and 6 males $[n=12])$. No differences were found in any test according to gender.

\section{Behavioral consequences of stress induction in mothers and their offsprings Control tests}

Several tests were run to control for physical alterations due to induction of stress that would not allow the animals to perform in a similar fashion. We measured locomotor capability and muscle development using the rotarod (control for fear learning, open field and Morris water maze), sensory function using the hotplate (control for pain sensation in the fear learning paradigm), and acoustic skills (startle habituation/Prepulse inhibition). Besides evaluating coordination and balance in the rotarod, this test has previously shown to be sensitive to deficits in motor learning, a task that has been reported to be dependent of the cerebellar integrity. Both groups of female adults (Figure 2A) and also derived litters (Figure 2B) presented similar muscle development and locomotor behavior. Additionally all groups presented good motor learning capabilities, indicating no deficiency in the cerebellar area, which is associated with motor learning. Furthermore, mothers subjected to preconceptional stress performed better in the rotarod during the first day of testing, appearing capable of focusing better on the task at hand (Figure 2A).

The hot plate test assesses the sensory response of mice. Both groups had a similar sensory function as measured in the hot plate (Figures 3A and 3B).

Table 1. Pregnancy outcome, offspring mortality rate and subjects tested from females subjected or not to peri-conceptional chronic stress for 12-15 days.

\begin{tabular}{lcccccc}
\hline Females & $\begin{array}{c}\text { Pregnancy } \\
\text { success rates }\end{array}$ & $\begin{array}{c}\text { Offspring } \\
\delta^{n}\end{array}$ & $\begin{array}{c}\text { Offspring } \\
+\end{array}$ & $\begin{array}{l}\text { Offspring } \\
\text { mortality rate }\end{array}$ & $\begin{array}{c}\text { Mothers } \\
\text { Tested(n) }\end{array}$ & $\begin{array}{l}\text { Juveniles/adults } \\
\text { tested(n) }\end{array}$ \\
\hline $\begin{array}{l}\text { Control } \\
(\mathrm{n}=5)\end{array}$ & $80 \%$ & 6 & 7 & $30.76 \%$ & 4 & 9 \\
\hline $\begin{array}{l}\text { Stress } \\
(\mathrm{n}=5)\end{array}$ & $60 \%$ & 15 & 9 & $50.00 \%$ & 3 & 12 \\
\hline
\end{tabular}



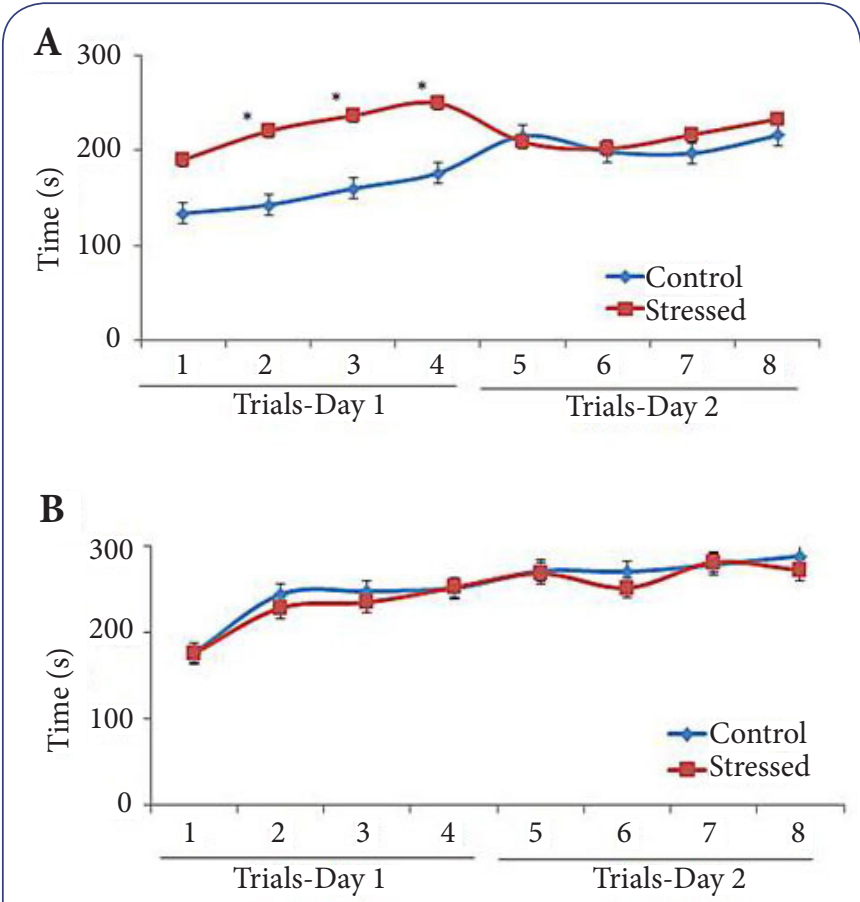

Figure 2. Evaluation of coordination and balance in the rotarod. Motor coordination was assessed by the rotarod. Stress and unstressed groups showed equivalent level of coordination and balance while on the rod.

(A) Stressed mothers outperformed the undisturbed mothers in the early stages of the test ( 4 trial/dayl), but their performance leveled out alongside the undisturbed during the second day of training.

(B) No differences were observed in motor skills among the juveniles derived from either stress or undisturbed females.

Pre-pulse inhibition (PPI) of startle response was used to assess the animal's general reflexes (startle) and acoustic skills. We used the pre-pulse inhibition of startle response test to measure the hearing ability of our study mice. Litters from both stressed and unstressed groups showed nearly identical responses to startle stimuli, but a deficient response compared to the inhibition level recorded for the adults. While no difference was observed between both groups of female mothers, these adults in general showed increased inhibition on their response after the pre-tone was administered compared to the litters (Figures 4A and 4B). In summary, our results indicate no impairment in locomotor skills as well as the general reflexes and acoustic skills for mothers and litters.

\section{Induction of anxiety related behaviors open field}

To evaluate normal exploratory behavior, motor function and anxiety traits we measured spontaneous activity in the open field. We used a large open field to provide more opportunity for long-distance movements that will allow us to detect components of fear- and/or anxiety-related behavior. In the open field test,

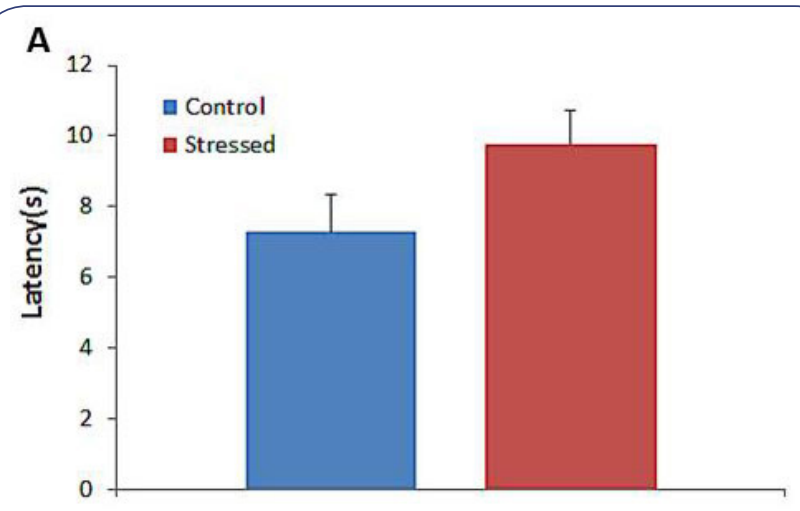

B

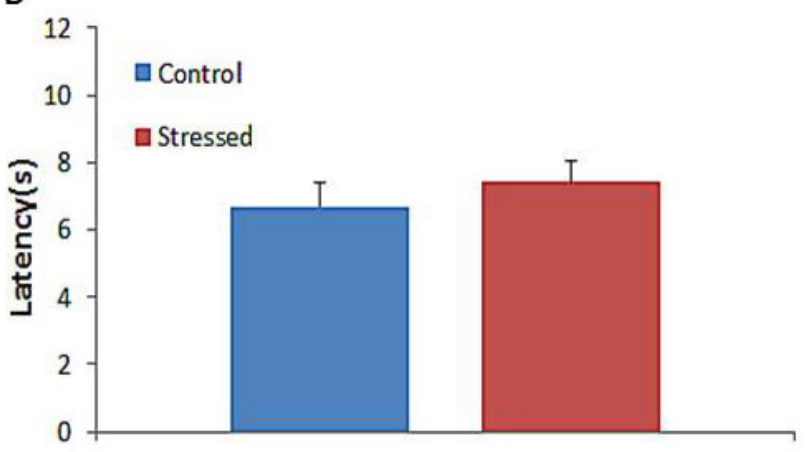

Figure 3. Assessment of sensory function in the hotplate. The Hot plate was used to measure response to nociception. (A) Stressed females had an analogous sensory function compared to undisturbed females, not showing appreciable differences in response to pain.

(B) Juveniles derived from the stressed group performed similarly to those derived from undisturbed mothers. female mice subjected to stress travelled significantly shorter distances than females in the control group (Figures 5A and 5B). Overall, the distance traveled and the total activity performed by the stressed group in a 30 minute period was shorter than female control group, indicating that the stress paradigms were indeed working at inducing stress in those animals. Upon measuring thigmotaxis (measure of the animal remaining in the edges of the field and a sign of anxiety), we observed that the time spent around the edges of the field was significantly shorter than for control females (Figure 5C). Decreased thigmotaxis normally suggests a lower anxiety level. However, because stressed females had overall less exploratory activity, this decreased thigmotaxis might be due to the lack of movement, despite the increased anxiety response shown in other tests.

When litters derived from female mice subjected to stress were tested, we did not observe any difference between distances traveled and total activity within the open field box compared to litters derived from females in the control group (Figures 5D and 5E), suggesting a comparable ambulatory activity. However, youngsters derived from stressed females showed a significant increase in thigmotaxis, indicating that, while their overall exploratory 


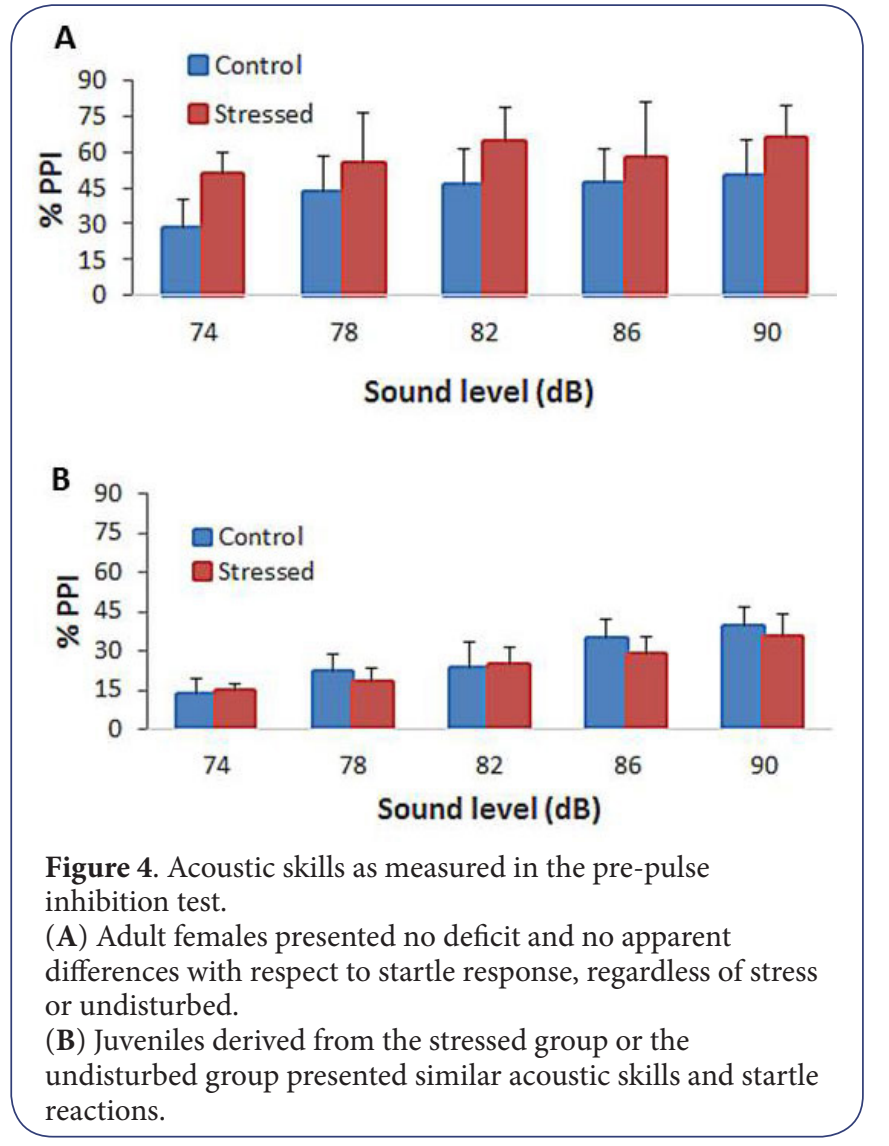

behavior appears normal, they are significantly more anxious and/or depressed than the offsprings derived from undisturbed females, seeking the edges of the field for their movements (Figure 5F).

\section{Light/Dark}

To evaluate anxiety-related behavior we used the light-dark test. This 10 minute test measured the tendency of the mouse to explore a novel environment against the aversive properties of a lit open field. In the light/dark test, stressed mothers spent less time in the light side of the box (Figure 6A). Young mice derived from these stressed mothers also spent a significantly shorter amount of time within the lit side of the box (Figure 6B) as compared to the control mice derived from un-stressed females. These results indicate that females and young animals coming from a stressed background are indeed significantly more anxious than control mice.

\section{Elevated plus maze}

This test measures fear and anxiety. It builds on the measurements taken on the light-dark paradigm by adding two additional components that measure anxiety, the openness and the height of the runways. Stressed Female mice did not venture out into the open arms of an elevated plus maze. They showed increased anxiety traits in comparison with undisturbed mice, spending
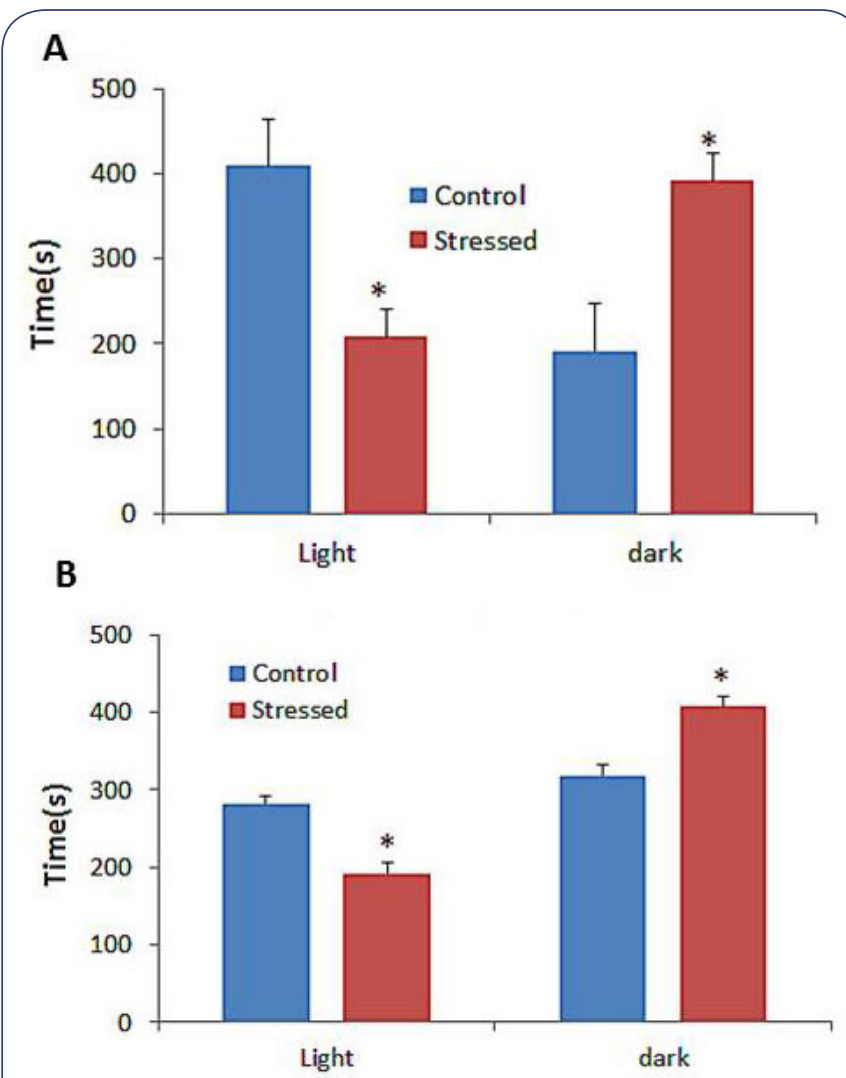

Figure 6. Relative anxiety levels as measured in a light dark test. (A) Mothers spent significantly more time in the dark side of the box compared to the unstressed control group $\left(t=2.01,{ }^{\star} \mathrm{p}<0.05\right)$. Likewise, (B) offsprings derived from the stressed group spent significantly more time in the dark side of the box compared to the control group, indicating a higher anxiety level. $\left(\mathrm{t}=1.729,{ }^{*} \mathrm{p}<0.05\right)$.

less time in the center of the apparatus, and more time in the closed areas of the maze (Figure 7A). An identical behavior was observed on the young mice derived from stressed mothers, spending less time in the center of the maze and longer time in the closed arms as opposed to the open arms (Figure 7B).

\section{Effects on learning and memory Fear conditioning}

Conditioning fear is a measure of learning and memory retrieval. In this test, mice are conditioned to freeze (measurement of learning and memory) to environmental cues (context box or a tone) that they associate with an aversive stimulus in the form of a foot shock. The test measures the ability of the mouse to learn and remember an association between that aversive experience and environmental/auditory cues. During the training session of this test, stressed female mothers appeared to be already conditioned to the test apparatus, freezing significantly more compared to controls from the time they were placed on the conditioning box (Figure 8A). This type of unexpected behavior might be explained because of the familiarity these stressed 

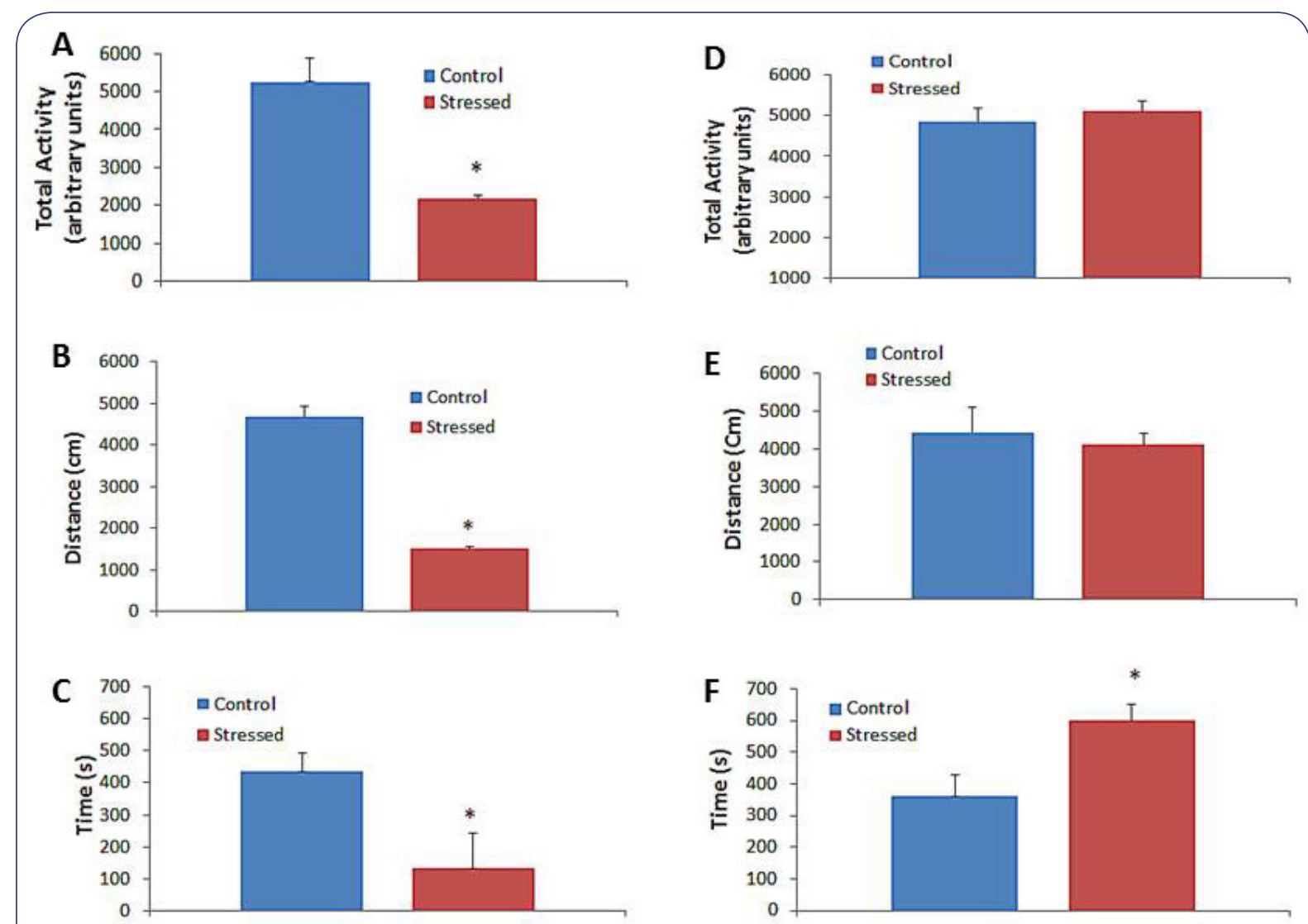

Figure 5. Exploratory behavior in the open field. Adult females were tested on the Open field. There was a significant decrease in (A) exploratory activity as well as (B) distance covered during the test on the mothers subjected to stress compared to the control females. (C) Thigmotaxis on female adults (tendency of animals to disproportionately explore the boundaries of an area) was also assessed in the open field. There was a significant decrease in time spent on the edges of the chamber from the stressed mothers compared to control. $\left(\mathrm{t}=2.353,{ }^{*} \mathrm{p}<0.05\right)$. This might be due to the lack of motion detected while determining exploratory activity and distance travelled. Juveniles derived from stressed and undisturbed mothers presented similar (D) exploratory activity as well as (E) total distance travelled. However, the litters from the stressed females spent significantly higher amount of time travelling on the edges of the open field (F), as compared to litters from the undisturbed females $\left(\mathrm{t}=1.745,{ }^{\star} \mathrm{p}<0.05\right)$.

females had with similar environments during the stress induction protocols (shock).

Contrary to these results, the offsprings from stressed mothers clearly showed an increased fear response during the conditioning training (Figure 8B), presenting a better pairing than offsprings from undisturbed mothers. These results confirmed previous tests that indicated a higher level of fear and anxiety in the young mice, showing increased fear awareness during the aversive stimuli. When stressed females were placed on the same box for test recall $24 \mathrm{hr}$ after training, their behavior was very similar to their performance during testing, with a high amount of their time inside the box freezing as a sign of learning (Figure $\mathbf{8 C}$ ). No differences were found in the recall $24 \mathrm{hr}$ after training to the sound administered during training (Figure 8E). As for the young animals derived from stressed or undisturbed mothers, there was not significant difference in their recall to the test either for the context (Figure 8D) or for the sound (Figure $\mathbf{8 F}$ ).

\section{Morris water maze}

The Morris water maze was used to evaluate spatial learning and reference memory abilities. During the training phase of the Morris Water maze, all animals from all groups were capable of learning the task at the same rate, showing overall reduction in the time taken to find a platform with the trial number (Figures 9A and 9B). A probe test was administered $24 \mathrm{~h}$ after training. During this probe test stressed females did not show a clear deficiency in spatial learning compared to unstressed females (Figure 9C). While not significant, stressed females showed a slight improvement in the performance of this test, spending more time looking for the platform in the correct quadrant. Likewise, no major differences were found in young mice, except for the offsprings derived from stressed mother spending more time in the opposite quadrant to where the platform was initially located (Figure 9D). 


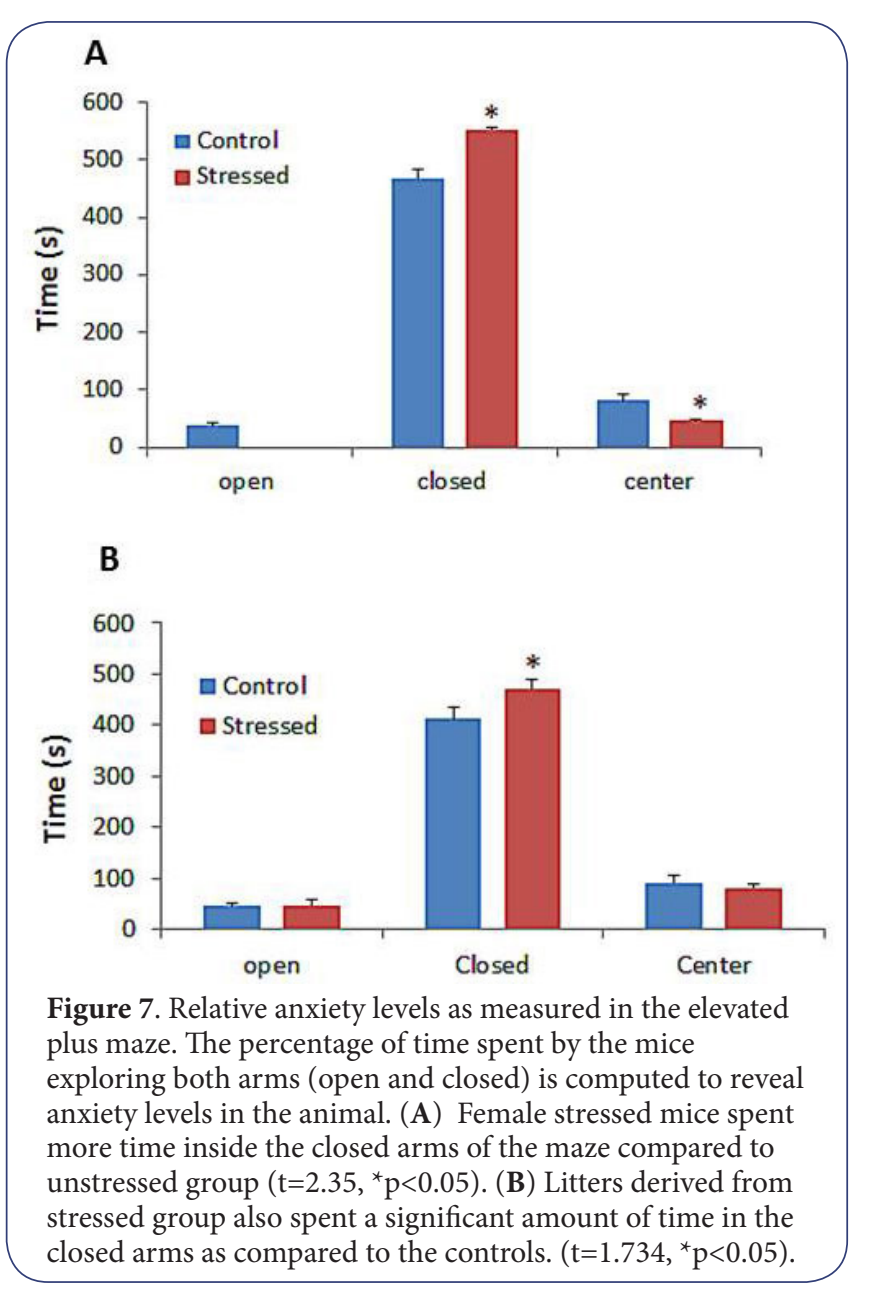

\section{Discussion}

Stress in an individual has been linked to the development of cognitive and other behavioral deficits. Moreover, it is well established that maternal prenatal stress causes many complications during pregnancy, not only for the mother, but also for the newborn. Stress before, during and after a pregnancy, has multiple quantifiable effects in the overall development, general health and behavior of the newborn [23]. Research has shown that the second and third trimesters of pregnancy are very important, because those are times of maximum susceptibility to the emerging brain [24]. It is then that environmental factors may disrupt important processes such as neuronal migration. If this occurs, there might be abnormalities in the prefrontal cortex, the hippocampus and entorhinal cortex. Those are brain areas that are affected in mental illnesses such as schizophrenia [25]. In this study we have focused primarily on how offsprings perform cognitively and behaviorally as adults. We have shown that periconceptional stressed mothers showed increased anxiety, and that mice born from these stressed mothers also had higher anxiety- and depression-like behaviors at their juvenile/ adult stage. The implication of these results is that, besides the genetic imprint of an individual, there may be epigenetic changes occurring even before conception that are being passed from mother to youngsters. As such, the genes themselves might not be changing, but the way the DNA is wound up together is, resulting possibly in alteration on the expression of some important genes.

Our study suggests that induction of stress in female mice was successful using the tests chosen. This was supported by increased anxiety-like behaviors. We also report that offsprings from

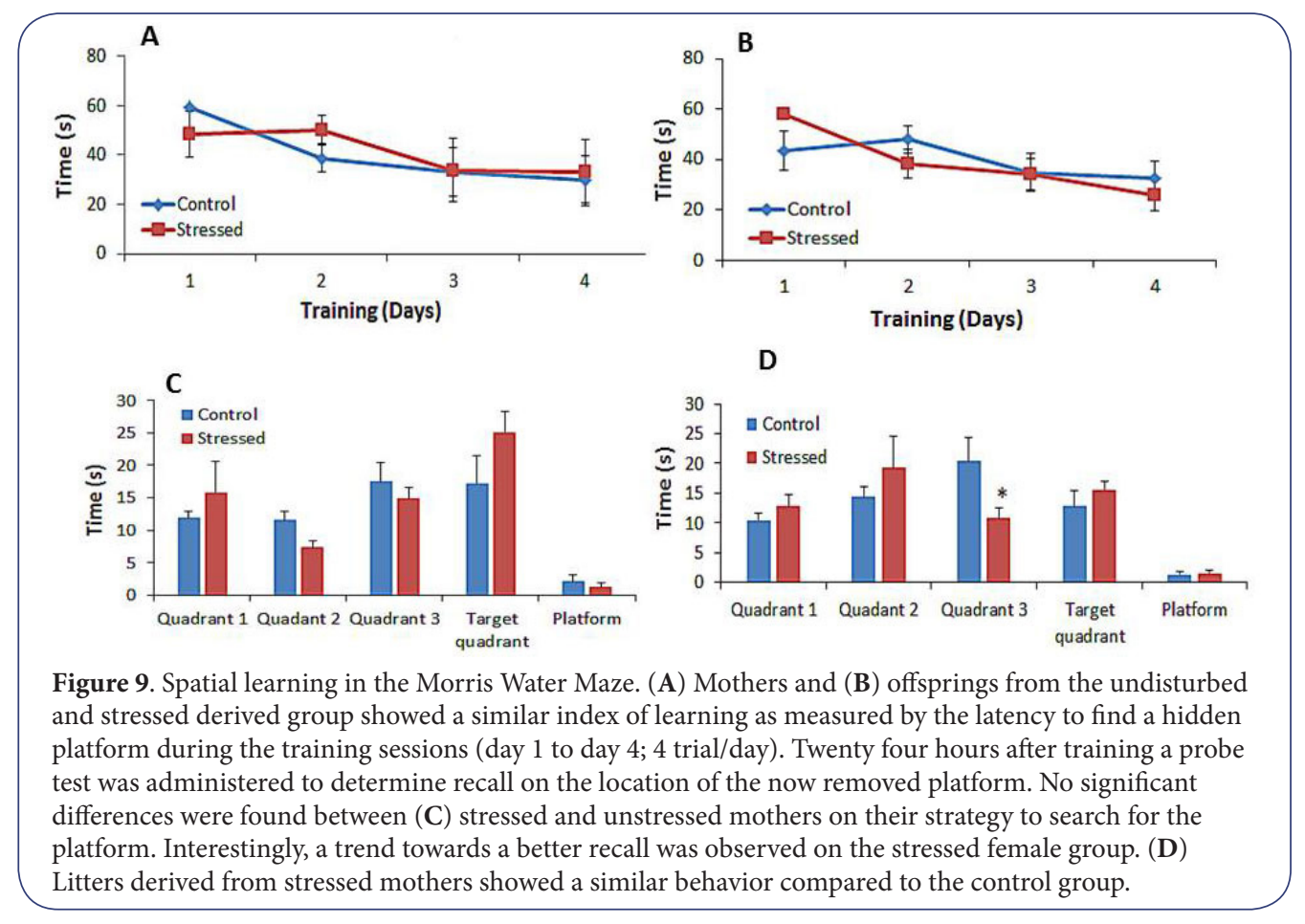




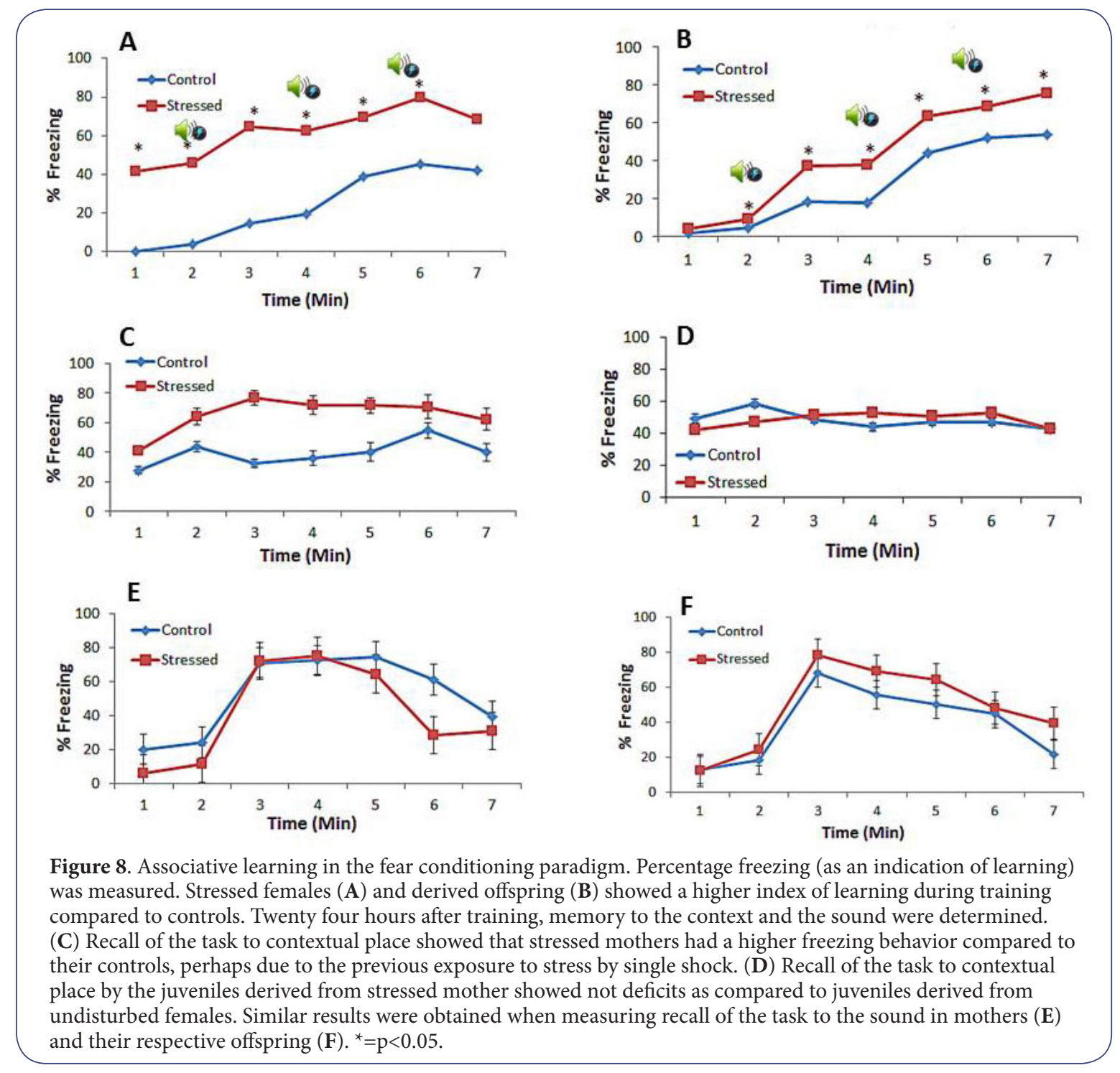

stressed mothers (both male and females, as no differences were found when analyzing the offsprings by gender) have elevated expression of anxiety and possibly depression, as shown by the anxiety tests and the decreased exploratory activity. Regarding psychosis-like behaviors as measured by PPI, our study shows that stressed females have similar inhibitory behavior compared to the control group. Interestingly, offsprings derived from both groups (control and stressed females) appear to have a deficit in acoustic prepulse inhibition. This apparent deficit in PPI could be associated to neuropsychiatry diseases in humans, in which patients are having difficulty ignoring external stimuli (schizophrenia, Tourette's syndrome, bipolar disorder). However, in our study we did not find a difference between offsprings derived from stressed females and undisturbed controls. This makes it problematic to link to psychotic complications. It has been established that, in rodents, increasing age and experience results in improved performance in the PPI test [26]. Thus, our data might reflect the fact that the offsprings, perhaps due to the age, are not capable of processing the stimulus correctly.

Interestingly, our results in the fear conditioning test also show a higher freezing behavior from animals exposed to stress and their offspring with respect to animals that were left undisturbed. This can be interpreted as stress building anxiety and resulting in alertness and attention. Our findings are in contradiction to some recent investigations in which mice exposed to five hours of multimodal stress presented altered dendritic morphology as well as cognitive function [23]. Additionally, other investigations have shown that stress can damage attention $[\mathbf{2 7}, \mathbf{2 8}]$, short-term memory [29], passive avoidance response [30], recognition memory [31], working memory [32], and spatial memory $[33,34]$. However, we need to point out that there are several levels of stress that can produce different results on these functions. Low stress levels can even be beneficial for normal functioning, while moderate and especially severe stress levels 
can produce detrimental effects. Thus, we suggest that these stressors experienced peri-conceptionally, while perhaps milder in nature as compared to other studies, produce susceptibility towards behavioral abnormalities in mothers suffering the stress as well as offsprings at the time of adolescence. While no learning disabilities were uncovered, increased anxiety may help on the onset of cognitive disorders. Future studies will be carried out to reveal correlations between increased anxiety, psychosis and physiological alterations within the brain.

Recently, there have been studies that have linked excess free radicals in the brain to anxiety and depression, all of which are underlying symptoms to larger psychotic disorders [35]. Likewise, it has been suggested that maternal stress produces alterations in certain serotonin and glutamate receptors in adult offspring [36]. These mice exhibited behaviors reminiscent of schizophrenia [36], depression-like behaviors [37], possibly due to dysfunction in receptors for these neurotransmitters. Altogether, there is a link between stress and neurological/physiological changes in the brain of the offspring, which are worth to decipher.

\section{Competing interests}

The authors declare that they have no competing interests.

\section{Authors' contributions}

A. Oderhowho performed the experiments, analyzed the data and wrote the manuscript. M.V. Tejada-Simon designed the study, analyzed the data, wrote the manuscript.

\section{Acknowledgement}

This study was supported by the small research grants- (UH) to M.V.T.S. The authors want to thank Luis Martinez for help on animal husbandry and training on the behavioral experiments.

\section{Publication history}

Editors: Vinay Parikh,Temple University, USA.

Kamilla Bargiel-Matusiewicz, University of Warsaw, Poland. Received: 06 November 2015 Revised: 11 December 2015 Accepted: 21 December 2015 Published: 30 December 2015

\section{References}

1. Anisman H, Zaharia MD, Meaney MJ and Merali Z. Do early-life events permanently alter behavioral and hormonal responses to stressors? Int J Dev Neurosci. 1998; 16:149-64. | Article | PubMed

2. Sanchez MM, Ladd CO and Plotsky PM. Early adverse experience as a developmental risk factor for later psychopathology: evidence from rodent and primate models. Dev Psychopathol. 2001; 13:419-49. | PubMed

3. Mansour H, Fathi W, Klei L, Wood J, Chowdari K, Watson A, Eissa A, Elassy M, Ali I, Salah H, Yassin A, Tobar S, El-Boraie H, Gaafar H, Ibrahim NE, Kandil K, El-Bahaei W, El-Boraie O, Alatrouny M, El-Chennawi F, Devlin B and Nimgaonkar VL. Consanguinity and increased risk for schizophrenia in Egypt. Schizophr Res. 2010; 120:108-12. | Article | PubMed Abstract | PubMed FullText

4. Bener A, Dafeeah EE and Samson N. Does consanguinity increase the risk of schizophrenia? Study based on primary health care centre visits. Ment Health Fam Med. 2012; 9:241-8. | PubMed Abstract | PubMed FullText

5. Buka SL, Seidman LJ, Tsuang MT and Goldstein JM. The New England Family Study High-risk Project: neurological impairments among offspring of parents with schizophrenia and other psychoses. Am J Med Genet B Neuropsychiatr Genet. 2013; 162B:653-60. | Article I PubMed
6. Malaspina D, Corcoran C, Kleinhaus KR, Perrin MC, Fennig S, Nahon D, Friedlander $Y$ and Harlap $S$. Acute maternal stress in pregnancy and schizophrenia in offspring: a cohort prospective study. BMC Psychiatry. 2008; 8:71. | Article | PubMed Abstract | PubMed FullText

7. Laplante DP, Barr RG, Brunet A, Galbaud du Fort G, Meaney ML, Saucier $J F$, Zelazo PR and King S. Stress during pregnancy affects general intellectual and language functioning in human toddlers. Pediatr Res. 2004; 56:400-10. I Article I PubMed

8. Mulder EJ, Robles de Medina PG, Huizink AC, Van den Bergh BR, Buitelaar JK and Visser GH. Prenatal maternal stress: effects on pregnancy and the (unborn) child. Early Hum Dev. 2002; 70:3-14. | Article | PubMed

9. Brown AS. Epidemiologic studies of exposure to prenatal infection and risk of schizophrenia and autism. Dev Neurobiol. 2012; 72:1272-6. | Article | PubMed Abstract | PubMed FullText

10. Ashdown H, Dumont Y, Ng M, Poole S, Boksa P and Luheshi GN. The role of cytokines in mediating effects of prenatal infection on the fetus: implications for schizophrenia. Mol Psychiatry. 2006; 11:47-55. | Article | PubMed

11. Khashan AS, McNamee R, Abel KM, Mortensen PB, Kenny LC, Pedersen MG, Webb RT and Baker PN. Rates of preterm birth following antenatal maternal exposure to severe life events: a population-based cohort study. Hum Reprod. 2009; 24:429-37. I Article I PubMed

12. Zammit S, Thomas K, Thompson A, Horwood J, Menezes P, Gunnell D, Hollis C, Wolke D, Lewis $G$ and Harrison G. Maternal tobacco, cannabis and alcohol use during pregnancy and risk of adolescent psychotic symptoms in offspring. Br J Psychiatry. 2009; 195:294-300. | Article | PubMed

13. Dorrington S, Zammit S, Asher L, Evans J, Heron J and Lewis G. Perinatal maternal life events and psychotic experiences in children at twelve years in a birth cohort study. Schizophr Res. 2014; 152:158-63. | Article | PubMed Abstract | PubMed FullText

14. Fink G. Stress consequences: mental, neuropsychological and socioeconomic. Ed. George Fink, Academic Press, San Diego, CA. 2010.

15. Mcllwain KL, Merriweather MY, Yuva-Paylor LA and Paylor R. The use of behavioral test batteries: effects of training history. Physiol Behav. 2001; 73:705-17. | Article | PubMed

16. Crawley JN. Mouse behavioral assays relevant to the symptoms of autism. Brain Pathol. 2007; 17:448-59. I Article I PubMed

17. Paylor R and Crawley JN. Inbred strain differences in prepulse inhibition of the mouse startle response. Psychopharmacology (Berl). 1997; 132:169-80. I PubMed

18. Anagnostaras SG, Wood SC, Shuman T, Cai DJ, Leduc AD, Zurn KR, Zurn JB, Sage JR and Herrera GM. Automated assessment of pavlovian conditioned freezing and shock reactivity in mice using the video freeze system. Front Behav Neurosci. 2010; 4. | Article | PubMed Abstract | PubMed FullText

19. Phillips RG and LeDoux JE. Differential contribution of amygdala and hippocampus to cued and contextual fear conditioning. Behav Neurosci. 1992; 106:274-85. | Article | PubMed

20. Kim JJ, Fanselow MS, DeCola JP and Landeira-Fernandez J. Selective impairment of long-term but not short-term conditional fear by the N-methyl-D-aspartate antagonist APV. Behav Neurosci. 1992; 106:591-6. | Article | PubMed

21. Paylor R, Tracy R, Wehner J and Rudy JW. DBA/2 and C57BL/6 mice differ in contextual fear but not auditory fear conditioning. Behav Neurosci. 1994; 108:810-7. | Article | PubMed

22. Chen YR, Swann AC and Burt DB. Stability of diagnosis in schizophrenia. Am J Psychiatry. 1996; 153:682-6. I Article I PubMed

23. Xu Y, Cheng X, Cui X, Wang T, Liu G, Yang R, Wang J, Bo X, Wang S, Zhou $W$ and Zhang Y. Effects of 5-h multimodal stress on the molecules and pathways involved in dendritic morphology and cognitive function. Neurobiol Learn Mem. 2015; 123:225-38. I Article I PubMed

24. Mrazek $P$ and Haggerty R.J. Risk and protective factos for the onset of mental disorders: Schizophrenia In Reducing risks for mental disorders: Frontiers for preventive intervention research-Chapter 6. National Academy Press, Washington, DC. 1994. 
25. Arnold SE and Trojanowski JQ. Recent advances in defining the neuropathology of schizophrenia. Acta Neuropathol. 1996; 92:217-31. | PubMed

26. Fitch RH, Threlkeld SW, McClure MM and Peiffer AM. Use of a modified prepulse inhibition paradigm to assess complex auditory discrimination in rodents. Brain Res Bull. 2008; 76:1-7. | Article | PubMed Abstract | PubMed FullText

27. Elling L, Steinberg C, Brockelmann AK, Dobel C, Bolte J and Junghofer M. Acute stress alters auditory selective attention in humans independent of HPA: a study of evoked potentials. PLoS One. 2011; 6:e18009. | Article | PubMed Abstract | PubMed FullText

28. Ljungberg JK and Neely G. Cognitive after-effects of vibration and noise exposure and the role of subjective noise sensitivity. J Occup Health. 2007; 49:111-6 | Article | PubMed

29. Sherwood N and Griffin MJ. Effects of whole-body vibration on shortterm memory. Aviat Space Environ Med. 1990; 61:1092-7. I PubMed

30. Bueno OF, Lobo LL, Oliveira MG, Gugliano EB, Pomarico AC and Tufik S. Dissociated paradoxical sleep deprivation effects on inhibitory avoidance and conditioned fear. Physiol Behav. 1994; 56:775-9. | Article I PubMed

31. Chen Y, Rex CS, Rice CJ, Dube CM, Gall CM, Lynch G and Baram TZ. Correlated memory defects and hippocampal dendritic spine loss after acute stress involve corticotropin-releasing hormone signaling. Proc Natl Acad Sci U S A. 2010; 107:13123-8. | Article I PubMed Abstract | PubMed FullText

32. Manikandan S, Padma MK, Srikumar R, Jeya Parthasarathy N, Muthuvel A and Sheela Devi R. Effects of chronic noise stress on spatial memory of rats in relation to neuronal dendritic alteration and free radicalimbalance in hippocampus and medial prefrontal cortex. Neurosci Lett. 2006; 399:17-22. | Article | PubMed

33. Chengzhi C, Yan T, Xuejun J, Xiang L, Youbin Q and Baijie T. Recovery of chronic noise exposure induced spatial learning and memory deficits in young male Sprague-Dawley rats. J Occup Health. 2011; 53:157-63. I Article I PubMed

34. Hagewoud R, Havekes R, Novati A, Keijser JN, Van der Zee EA and Meerlo $P$. Sleep deprivation impairs spatial working memory and reduces hippocampal AMPA receptor phosphorylation. J Sleep Res. 2010; 19:280-8. | Article | PubMed

35. Cabungcal JH, Counotte DS, Lewis E, Tejeda HA, Piantadosi P, Pollock C, Calhoon GG, Sullivan E, Presgraves E, Kil J, Hong LE, Cuenod M, Do KQ and $O^{\prime}$ Donnell $P$. Juvenile antioxidant treatment prevents adult deficits in a developmental model of schizophrenia. Neuron. 2014; 83:10731084. | Article | PubMed Abstract | PubMed FullText

36. Holloway T, Moreno JL, Umali A, Rayannavar V, Hodes GE, Russo SJ and Gonzalez-Maeso J. Prenatal stress induces schizophrenia-like alterations of serotonin $2 \mathrm{~A}$ and metabotropic glutamate 2 receptors in the adult offspring: role of maternal immune system. J Neurosci. 2013; 33:108898. | Article | PubMed Abstract | PubMed FullText

37. Sun H, Guan L, Zhu Z and Li H. Reduced levels of NR1 and NR2A with depression-like behavior in different brain regions in prenatally stressed juvenile offspring. PLoS One. 2013; 8:e81775. | Article | PubMed Abstract | PubMed FullText

\section{Citation:}

Oderhowho A and Tejada-Simon M.V. Periconceptional stress in $\mathrm{C} 57 \mathrm{BL} / 6 \mathrm{~J}$ female mice leads to altered behavioral responses in their offsprings. J Psychiatry Brain Funct. 2015; 2:10. http://dx.doi.org/10.7243/2055-3447-2-10 